\title{
Hydropower Production Optimization from Inflow: Case Study of Songloulou Hydroplant
}

\author{
Daniel Eutyche Mbadjoun Wapet ${ }^{1}$, Salomé Ndjakomo Essiane ${ }^{1,2}$, René Wamkeue ${ }^{1,3}$, \\ Patrick Juvet Gnetchejo ${ }^{4}$
}

${ }^{1}$ Laboratory of Electrical Engineering, Mecatronic and Signal Treatment, National Advanced School of Engineering, University of Yaounde 1, Yaoundé, Cameroon

${ }^{2}$ Higher Technical Teacher Training College of Ebolowa, University of Yaounde 1, Yaounde, Cameroon

${ }^{3}$ School of Engineering, University of Quebec in Abitibi-Temiscamingue (UQAT), Rouyn-Noranda, Canada

${ }^{4}$ Laboratory of Technologies and Applied Sciences, University of Douala, Douala, Cameroon

Email: daniel_mbadjoun@univ-douala.com, salomendjakomo@gmail.com,rene.wamkeue@hotmail.com,

patrijuvet@yahoo.fr

How to cite this paper: Mbadjoun Wapet, D.E., Essiane, S.N., Wamkeue, R. and Gnetchejo, P.J. (2020) Hydropower Production Optimization from Inflow: Case Study of Songloulou Hydroplant. Journal of Power and Energy Engineering, 8, 37-52. https://doi.org/10.4236/jpee.2020.88003

Received: June 19, 2020

Accepted: August 22, 2020

Published: August 25, 2020

Copyright $\odot 2020$ by author(s) and Scientific Research Publishing Inc. This work is licensed under the Creative Commons Attribution International License (CC BY 4.0).

http://creativecommons.org/licenses/by/4.0/

\section{(c) (i) Open Access}

\begin{abstract}
The model of nonlinear power generation function is developed to generate optimal operational policies for Songloulou inflow in Cameroon and test these policies in real time conditions. Our model is used to adjust operational regimes for the Songloulou reservoir under varying flows (turbined and deversed) using a dynamic program. A more interesting approach, proposed in this article, consists of combining both the principle of decomposition by resources (or quantities) and the technique of dynamic programming. Dynamic programming is an appropriating optimization algorithm that is used for complex non-linear inflow operational policies and strategies. In this case study, our optimization model is used and confirmed maximizing large scale of hydropower in a period of time step by the integration of several. The high non linearity of our study object is the first stage of difficulty which brought us to combined least squared and Time Varying Acceleration Coefficients Particle Swarm (TVACPSO) to obtain appropriate production function which generated optimal operational policies for the Songloulou hydropower in sub-Saharan region and after we tested it in the company policies operational at real time conditions. The model could be successfully applied to other hydropower dams in the region.
\end{abstract}

\section{Keywords}

Hydropower, Reservoir, Optimization, Simulation, Dynamic

Programming 


\section{Introduction}

Furthermore, Cameroon is the second highest hydro potential in Central Africa after the Democratic Republic of Congo [1]. With its vast watershed representing more than $25 \%$ of the total area of the country and its numerous rapids, the Sanaga, the largest river in the Republic of Cameroon, constitutes a first-rate hydroelectric energy reservoir. The Songloulou hydroelectric dam is the largest hydroelectric plant in Cameroon. Located on the Sanaga in the Massock Songloulou commune, about $55 \mathrm{~km}$ to the northwest and upstream of Edea, the Songloulou hydroelectric power station has a capacity of $394 \mathrm{MW}$ as run-of theriver hydroplant. Its retention dimension is 528 meters. The Songloulou power station has 8 Francis groups with a capacity of $49.5 \mathrm{MW}$. Songloulou is now the biggest power plant which makes him the center piece in production planning. Cameroon faces a deficit in electrical energy despite government efforts to resolve this through the construction of new power plants currently underway. There is an urgent need to start economic and social development towards an emergence planned for 2035. In view of the above, it would be important to have a tool that corresponds to the environmental, technological and economic realities to match the power demand. Many research themes relate to improving energy quality and increasing electricity production capacity for both renewable and fossil sources [2]-[11].

Hydro power is represented by a nonlinear function of the turbined flow and of the storage in the reservoirs, and sometimes also of the spillage. In literature, many works are implemented on the modeling and scheduling of the hydropower in the long, mid and short terms planning by taking into account hill curves, input/output relationship data collection, forbidden operating zones [12] [13]. Usual procedures of mathematic modeling are to represent the power as a family of nonlinear concave functions of the discharge, one at each given head [14] [15] [16], or as a unique function of both discharge and storage [17]. Formulations as seen in literature depend on the data sets of the hydro plant, as shown in [18] [19] [20]. In this paper, a simulation of the using of the best alternatives in the hourly dispatch of Songloulou hydro plants is performed, and the deviations from the gap operation obtained are presented under statistical correlation factor. The objective of this paper is to build a combined optimizationsimulation dynamic model with the following aims:

- Construct a mathematical model for each hydro unit power factor by least squared with Time Varying Acceleration Coefficients Particle Swarm

(TVACPSO) regression technique from values obtained in company data during chosen highly non linearity operational time.

- Generate an optimal policy planning, which consists to maximize the production of each unit at the level of the upstream by developing mathematical model of downstream as well as the possible flow and the spillage took account

- Compare the generate policies with the currently existed historical input/ output data. 
The design model uses the dynamic structure due to the stochasticity of the reservoir inflow with his spillage for respect the maximum level of upstream. The Songloulou hydroplant is used here as a case study. Eneo is responsible for the management, operation and maintenance of the hydrauliclayout of the power plant. Currently, the reservoir releases are done to match the energy demands.

This paper is organized as follows: Section 2 describes the hydro power generation function and makes review of mathematical formulations. Section 3 presents the dynamic programming used here in our optimal planification. We show how solving the generalized problem with physical and hydraulic constraints can be done effectively inside a scheme which combine both PD's technic and dkomposition's method with resources. Section 4 is the phase of development of the model in detail. Numerical results are shown then discuss and the conclusion are given in Section 6.

\section{Production Function of Hydro Generation}

The goal of the production function is to quantify the generation power of a hydropower plant. The calculus procedure takes account the difference between forebay and tailrace levels and the water discharge by applying the losses of the turbine-generator or group set and penstock [14] [21] [22] [23]:

$$
P=k \cdot \eta_{t} \cdot \eta_{g} \cdot\left[h_{f b}(V)-h_{t r}(u)-h_{p l}\right]
$$

For individual generating unit of the plant by taking into account the losses of the turbine-generator or group set and the penstock, Equation (1) can be rewritten as follows:

$$
P=k \cdot \eta^{G} \cdot h_{g} \cdot q
$$

This transformation of net head to gross head does not compromise the record of plant operations because, in general, values of turbine efficiency, generator efficiency, and penstock head loss are not recorded separately in the database for each hour (or half-hour) of operation [16].

Usually, almost head values are calculated by computational models developed for the hydroelectric system's operation.

\subsection{Data Collection and Area of Modeling}

Development of hydroelectricity power plant model required the following records data use during one year since June 2017 to May 2018 around 8760 hours:

- Hill chart of typical turbine unit of the plant,

- Hourly power generation, upstream elevation, downstream elevation, turbined flow, deversing flow, gross head of each unit.

These data serve to study the schedule of hydro plant with:

- Turbo-generator model,

- Tailrace elevation model. 


\subsection{Songloulou Hydroelectric Plant Model}

Songloulou is a run-of-the river plant which produces the high generation electricity in the country. Scheduling of hydro power plants needs an expression output power in terms of head and discharges, i.e., hydro turbine model, reservoir elevation model \&tailrace elevation model. Mathematical model required to explain the proper scheduling to help maximize the power generation.

Modeling of the hydroelectric plant is a very complex task and as such there is no uniform modeling as each one is unique to its location and requirement. The diversity of these designs makes it necessary to model each one individually. The parameters of modeling are nonlinear and highly dependent on the control variables. In case of the power station study, the coefficients have to be determined by collating precedent announcing plant data.

\section{1) Turbo-generator model}

Under uncertain raining conditions, maximizing of hydropower becomes a challenging task which is the scope of all producer. Of course, the mathematical formulation took into account the head variation over the operation periods as the net head changes from hour to hour and affected power generation. Additionally, the formulation considered the operation of 8 heterogeneous generating units and the nonlinear power generation function of each unit. A three-dimensional interpolation technique is used to accurately represent the nonlinear power generation function of each unit, taking into account the time-varying head as well as the nonsmooth limitations for power output and power release. It is very important to model the turbo-generator as it is a part of the objective function in the hydroelectric scheduling problem. This model relates the magnitude of power generated in terms of head and discharge as shown previously. As in this case, power is a dependent variable, whereas head and discharge are the independent variables, so it can be modeled using multiple regression analysis. The mathematical model of the individual hydro plant is obtained by minimizing the average square error of the power values provided by the model as compared with the collecting data as in [15] with TVACPSO [24].

$$
P_{i}=a_{0} H b * Q_{i}+a_{1} Q_{i} * H b^{3}+a_{2} H b^{2} * Q_{i}^{2}+a_{3} Q_{i}^{3}+a_{4} H b^{2} * Q_{i}^{4}+a_{5} Q_{i}^{5}
$$

In order to ensure that we have an appreciable mathematical model, we could calculate the factor of correlation. By convention, we will say that the relation between single $\mathrm{X}$ and $\mathrm{Y}$ is:

- perfect if $r^{2}=1$.

- very strong if $r^{2}>0.8$.

- strong if $\mathrm{r}^{2}$ is between 0.5 and 0.8 .

- medium intensity if $\mathrm{r}^{2}$ is between 0.2 and 0.5 .

- weak if $\mathrm{r}^{2}$ is between 0 and 0.2 .

- Null if $r^{2}=0$.

We evaluate quality of our model by calculating coefficient of correlation.

Table 1 presents each individual turbo-generator model below. 
Table 1. Individual unit model of Songloulou hydro plant.

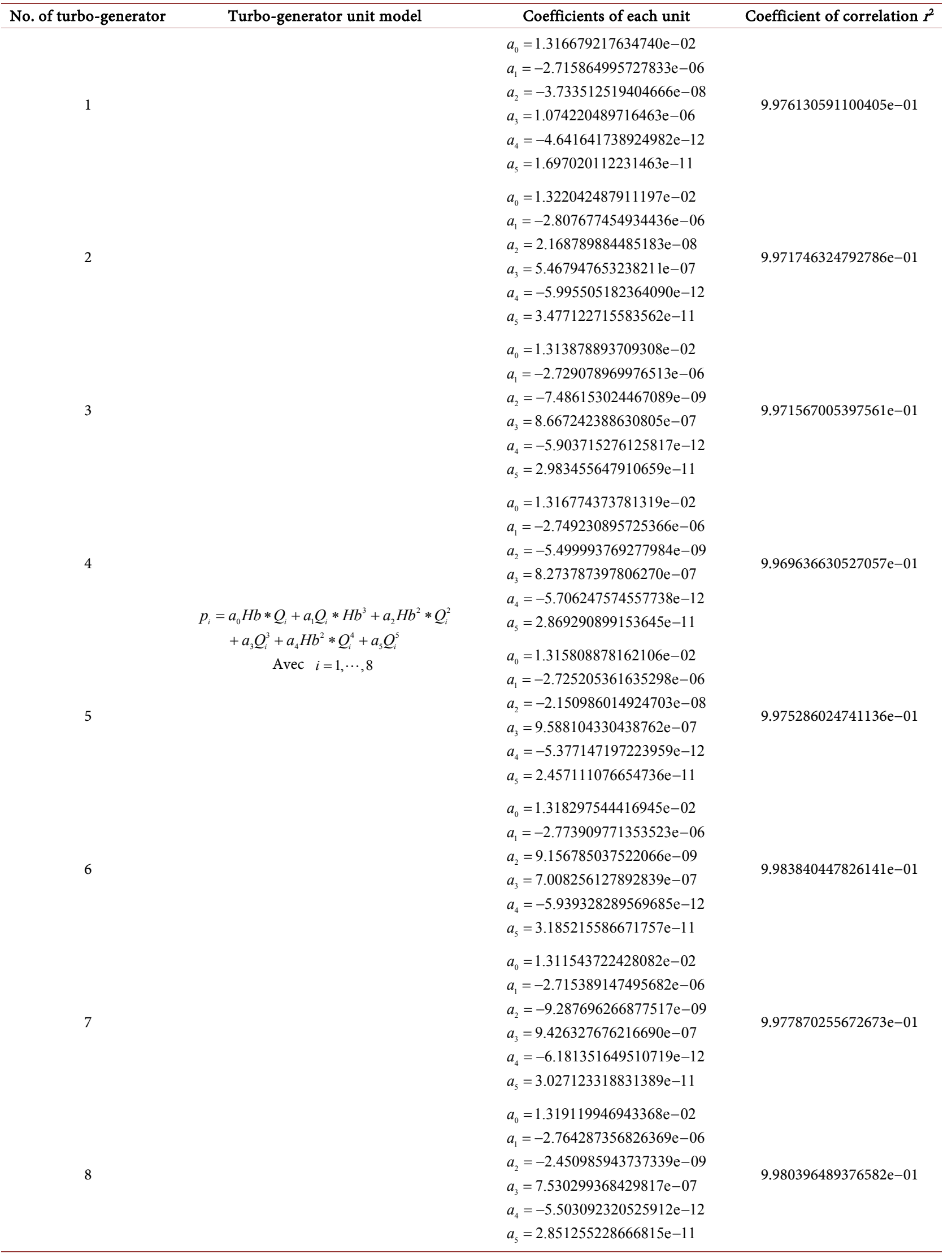




\section{2) Tailrace elevation model}

As per design of the hydroelectric plant, the station discharge either through turbine or spillway can raise the tailrace elevation, which decreases the effective head. This model related the water level in the tailrace channel with total discharge (discharge through turbine \& spillway) through hydro power plant. Tailrace elevation is the independent variable and total discharge is a dependent variable. The model can be obtained by the same development as turbo-generator model by using non linear least squared.

$$
\begin{aligned}
h_{t l}= & -1.441091209563667 \times 10^{-5} Q_{t o t}^{1.68178}+4.569880405719042 \times 10^{2} Q_{t o t}^{0.00969} \\
& +3.001647346575221 \times 10^{-11} Q_{t o t}^{3.21}
\end{aligned}
$$

with correlation coefficient $r^{2}=0.9999999087038359$.

Given the slight variation in the upstream elevation, we had prohibited the determination of its model according to the volume of the tank. In our optimization, the hydro plant manager introduces the level of the upstream elevation and the specific total flow before computing the planing program.

\section{Optimal Planification of Songloulou Hydro Plant}

\subsection{Concepts of Dynamic Programming Dispatching}

Short-term planning (horizon of a few days with an hourly step) takes into account the global decisions made by medium-term planning and provides a plant operation plan with all the considerations linked to the choice of turbine generator sets to be engaged or remove for maintenance, prohibited areas of operation from groups, etc. This work took account decision variables as turbined flow and deversing flow to expect maximizing the power generation of Songloulou plant. One of the best method of dispatching of this kind of problem is dynamic programming which took account all sub-problems during the process.

Dynamic programming has stages and states. Each sub-problem is a step whereas at each step, a state of the system is defined. The solution is built by back induction, that is to say that the resolution of the problem begins at the last step and the sub-problems are solved by going back one step each time, until all the sub -problems be resolved. One of the major problems with this method is that quickly the problem becomes difficult to solve given the number of variables. In fact, there is a need to discretize state space. For example, in hydroelectric optimization, we must discretize the volume, the unit flow, the total flow, without forgetting that we must consider the number of turbines as well as the periods. Obviously, this enumeration depends on the modeling of the problem. One of the advantages of dynamic programming is that non-linearities are easily handled, since all combinations of variables are evaluated. The principal inconvenient of dynamic programming is when the number of state variable become high [25] [26]. In this paper, modified dynamic programming is proposed by avoiding high dimension of the variable state. So we have divided the main problem into many subproblems with equal constraints. 
Literature shows that some authors of [27] [28] [29] use dynamic programming to determine the number of turbines in operation on an hourly basis. To do this, the steps are the hours, the states are the number of turbines running at each step and the decision variables are the number of starts and stops of turbines at each step. A compromise between the efficiency of the power produced and the starts is minimized in the objective function of the dynamic programming problem. The authors do not consider the water constraints, because the upstream elevation does not vary much over hourly periods. In our modelization, we consider the variations of upstream elevation over hourly periods but not took account starts up and start down of turbines cost.

\subsection{Formulation of Songloulou Problem of Maximization}

The conventional formulation problem $(\mathrm{C})$ of dynamic programming is:

$$
\begin{gathered}
\max \sum_{j=1}^{8} P_{j}\left(Q_{j}\right) \\
\sum_{i=1}^{8} q_{i}=Q_{T} \\
q_{i} \in D_{i}
\end{gathered}
$$

The conventional formulation has a flaw that is open to criticism. Indeed, the use of the equality constraint (6) to model the total flow to be discharged by the power station can generate a certain ineffectiveness due to the presence of the prohibited zones or global constraints on a subset of groups ( like the constraints of terminals on the power to generate).

The second ineffective situation of the model (C) is obtained by combining the equality constraint (6) with an overall power constraint. To do this, we consider two identical groups whose power-flow function is illustrated in Figure 1. The global constraint on the two groups is of type:

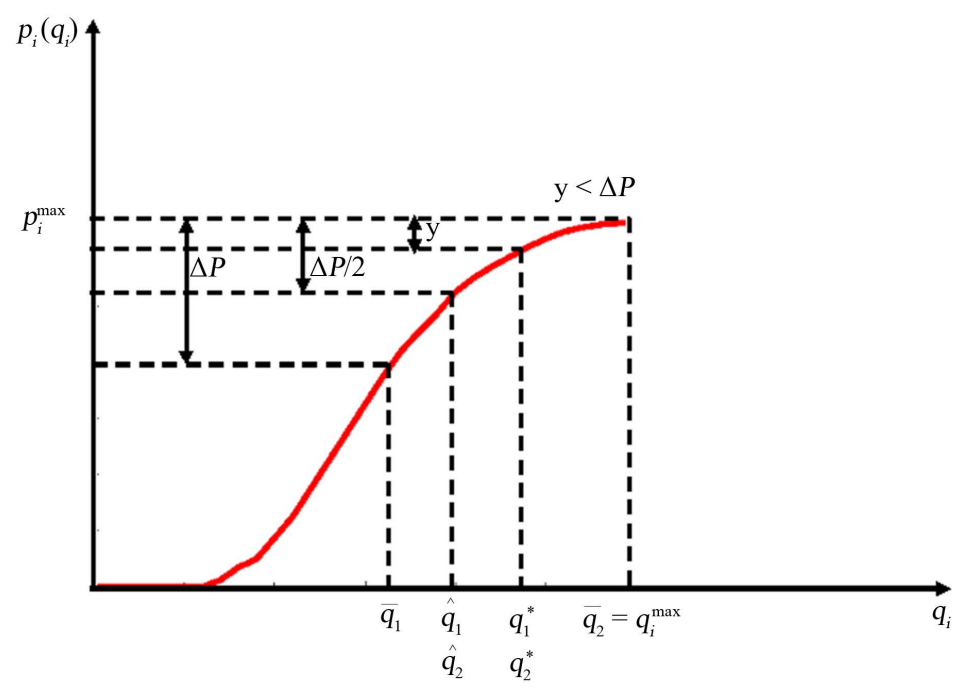

Figure 1. Example with global power constraint. 


$$
p_{1}\left(q_{1}\right)+p_{2}\left(q_{2}\right) \leq 2 p_{1}^{\max }-\Delta P
$$

With $p_{1}, p_{2}$ the power of the two groups. $\Delta P=p_{2}-p_{1}$.

The solution of the problem, neglecting the global constraint (8), consists in sharing the production between the two groups, that is to say $q_{1}^{*}=q_{2}^{*}=\frac{Q_{T}}{2}$. The solution of the problem (C) to which we add the constraint [8] is $\left(\bar{q}_{1}, \bar{q}_{2}\right)$ thus totaling a power of $\left(2 p_{i}^{\max }-\Delta P\right)$. An alternative solution $\left(\hat{q}_{1}, \hat{q}_{2}\right)$ (satisfying the constraint (8)) generates the same power by discharging less flow. This solution is also obtained by substituting the equality constraint (6) with an inequality.

The two examples show that the formulation of the constraint (6) in the form of equality can generate a certain ineffectiveness in the loading of the groups. For this reason, in what follows and along the chapters of this thesis, we opt for the formulation of this constraint in the form of inferior or equal inequality $(\leq)$.

Our proposed formulation optimization problem $(G)$ of Songloulou hydro plant is:

$$
\max \sum_{j=1}^{8} P_{j}\left(Q_{j}\right)
$$

With $Q_{j}$ the total allocated flow of each turbine and $P_{j}$ the production function of each unit.

The constrained use in our problem is:

$$
\begin{gathered}
\sum_{j=1}^{8} Q_{j} \leq Q_{t o t} \\
Q_{j} \geq 0 \\
Q_{i} \in D_{i}
\end{gathered}
$$

where $D_{i}$ is admissible interval of turbine, $Q_{i}$ unit discharge, $Q_{\text {tot }}$ total discharge.

Note that the sum of the flows can be lower than the total flow allocated, because in some cases, it is necessary to pour water from the tank directly if you do not want to lose power. Unlike the model (C), the set point constraint (10) is an inequality.

Then, after having mathematically modeled our problem, we were able to reflect on the dynamic programming of it. We therefore determined:

- Steps

- The states

- Decision variables

Our goal is to determine the flow to allocate per turbine from the total flow $\left(Q_{\text {tot }}\right)$.

So we have the decision variable $Q_{j}$, which is the amount of flow allocated to the turbine. Each turbine is a step. The states are $Q_{r}$ the flow remaining to be allocated.

For the programming language, we chose to use python 3 because it is an ob- 
ject-oriented language that is easy to use and very efficient for mathematical calculations.

A more interesting approach, proposed in this article, consists of combining both the principle of decomposition by resources (or quantities) and the technique of dynamic programming. We show how solving the generalizes problem, with physical and hydraulic constraints can be done effectively inside a scheme which combine both PD's technic and dkomposition's method with resources.

A direct extension of the PD algorithm (to this generalized model) consists in associating with each global constraint of the problem a state variable. This represents, at each stage of the PD, the quantity of water used by the groups supplied by a given channel or the power generated by the groups of a given network. So, we are left with a state vector of dimension equal to the number of coupling constraints of the problem.

Although this approach is relatively simple to implement, its drawback is that the computation time increases rapidly with the dimension of the state vector. A more interesting approach, proposed in this paper, consists of combining both the principle of decomposition by resources (or quantities) and the dynamic programming technique.

At the upper level, the total available $Q_{r}$ speed is shared between the different channels; then, the flow rate of each channel is distributed between the subsets of groups connected to the same electrical network; finally, each bit rate relating to this last partition is allocated between the corresponding groups. individually, these successive allocations must be carried out optimally.

Formally, we can announce the principle of decomposition as follows: the initial problem $\mathrm{G}$ is subdivided into sub-problems SC so that each of them involves only the decision variables $\left(q_{i}\right)_{i \in I}$ representative the groups of the water supply of channel $l$. In the same way, the sub-problem SC is decomposed into subproblems SR such that each restricted sub-problem contains only the decision variables linked to the network $\mathrm{r}$ of the channel $l$.

Thus, let $P_{r}^{l}\left(Q_{T}\right)$ be the optimal production of the network $r$ of the channel $I$ to which a flow resource $Q$ has been allocated. This production is calculated by solving the following sub-problem:

$$
\left\{\begin{array}{l}
\max \sum_{i \in J_{r}^{l}} p_{i}\left(q_{i}\right) \\
\sum_{i \in J_{r}^{l}} q_{i}=Q_{T} \\
q_{i} \in D_{i}, \forall i \in J_{r}^{l}
\end{array}\right\} \mathrm{SR}
$$

At the level of channel $l$, we denote $V_{r}^{l}$ the possible values of the bit rate to be allocated to the groups of the network $r$ of channel $l$. This set is defined by the following domain:

$$
V_{r}^{l}=\left\{Q_{T} \in\left[\sum_{i \in J_{r}^{l}} p^{\min }, \sum_{i \in J_{r}^{l}} p^{\max }\right]: P_{r}^{l} \in D P\right\}
$$

Thus, the channel $l \in L$ works optimally by solving the sub-problem: 


$$
\left\{\begin{array}{l}
\max \sum_{i \in R_{l}} p_{i}\left(q_{i}\right) \\
\sum_{i \in R_{r}^{l}} q_{i}=Q_{T} \\
q_{i} \in V_{r}^{l}, \forall i \in R_{l}
\end{array}\right\} \mathrm{SC}
$$

Our procedure took into account the combination of decomposition and dynamic programming to provide a solution to the planning of Songloulou groups as described above.

\section{Results and Discussion}

After the implementation of our proposed problem with each production unit and the tailrace elevation using here to calculate individual output power, We implement an GUI interface, as shown in Figure 2.

Our GUI interface allows adjusting in input the current value of tailrace elevation and total inflow of the hydro plant and to obtain in the output the current unit inflow, total inflow, unit power, and total power according to the right discretization as shown in Figure 3.

To improve our proposed method, we compare our results with the company's results in the following Table 2.

Serie 1 is the tailrace elevation of Songloulou plant.

Serie 2 is the output power of the Songloulou hydro power.

Serie 3 is the output power result of our proposed optimization.

Table 2 shows the higher quality of production with our proposed method. From Table 2, we can see that the results are very good, because in the tests that

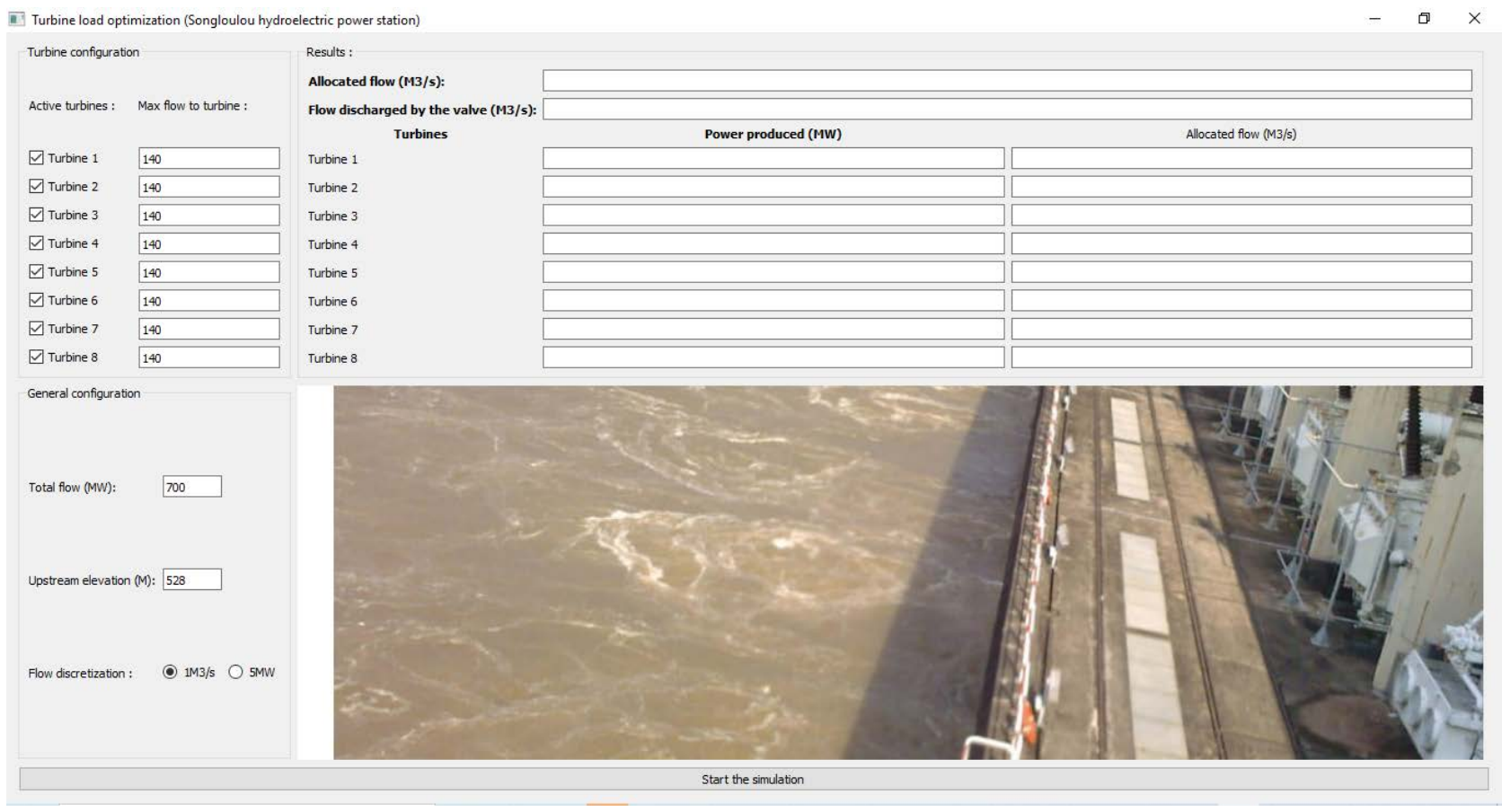

Figure 2. Gui of our dynamic programming dispatching. 


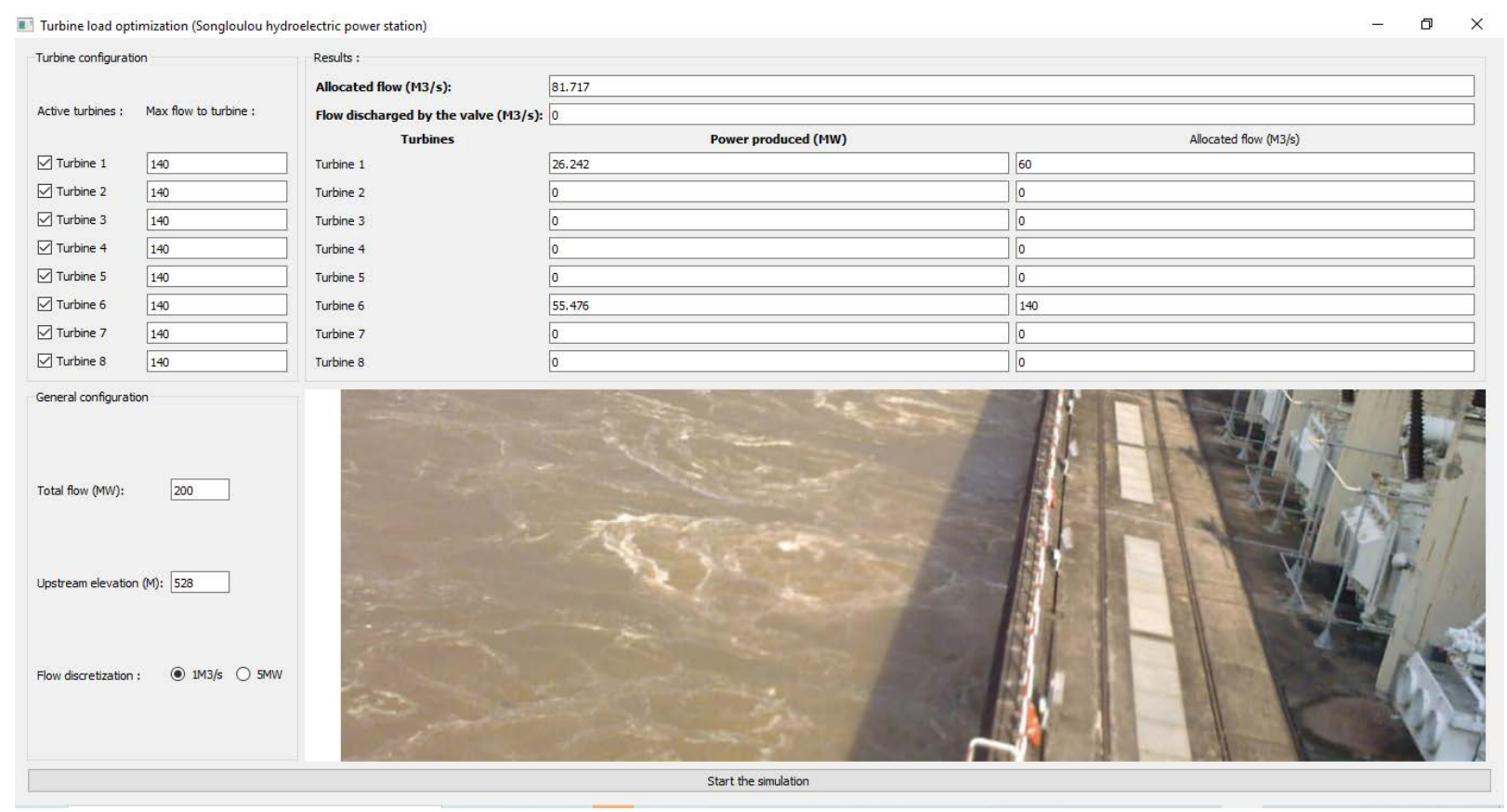

Figure 3. Sample of dynamic programming dispatching simulation.

Table 2. Comparison of results between our proposed algorithm and company implementation.

\begin{tabular}{|c|c|c|c|c|c|c|c|c|c|c|c|c|}
\hline Allocated coast & Owner method & Qtot & P1 & $\mathrm{P} 2$ & P3 & P4 & P5 & P6 & P7 & P8 & Qdev & Ptot \\
\hline \multirow[t]{2}{*}{527} & SLL & 1679 & 31 & 34 & 34 & 42 & 38 & 29 & 44 & 44 & 837 & 296 \\
\hline & Proposed & & 49 & 49 & 49 & 49 & 49 & 49 & 49 & 49 & 559 & 392 \\
\hline \multirow[t]{2}{*}{527.5} & SLL & 1545 & 48 & 46 & 49 & 44 & 46 & 47 & 48 & 45 & 463 & 373 \\
\hline & Proposed & & 49 & 49 & 49 & 49 & 49 & 49 & 49 & 49 & 425 & 392 \\
\hline \multirow[t]{2}{*}{528} & SLL & 1364 & 47 & 47 & 48 & 46 & 48 & 48 & 46 & 47 & 287 & 377 \\
\hline & Proposed & & 49 & 49 & 49 & 49 & 49 & 49 & 49 & 49 & 244 & 392 \\
\hline \multirow[t]{2}{*}{528} & SLL & 1105 & 49 & 46 & 48 & 47 & 47 & 46 & 47 & 48 & 20 & 378 \\
\hline & Proposed & & 49 & 49 & 49 & 49 & 42 & 49 & 49 & 49 & 0 & 385 \\
\hline \multirow[t]{2}{*}{527.5} & SLL & 1006 & 45 & 41 & 42 & 46 & 48 & 43 & 47 & 42 & 0 & 354 \\
\hline & Proposed & & 48.9 & 38.7 & 48.9 & 48.9 & 18.9 & 48.9 & 48.9 & 48.9 & 0 & 351 \\
\hline \multirow[t]{2}{*}{528} & SLL & 817 & 32 & 39 & 34 & 33 & 35 & 38 & 40 & 35 & 823 & 286 \\
\hline & Proposed & & 36.776 & 35.733 & 35.391 & 35.733 & 0 & 47.83 & 45.419 & 48.865 & 0 & 286.235 \\
\hline \multirow[t]{2}{*}{528} & SLL & 1003 & 44 & 46 & 42 & 45 & 44 & 42 & 45 & 43 & 0 & 351 \\
\hline & Proposed & & 44.164 & 44.156 & 44.16 & 43.809 & 80 & 49 & 49 & 49 & 0 & 351.539 \\
\hline \multirow[t]{2}{*}{527.5} & SLL & 679 & 19 & 0 & 40 & 47 & 35 & 48 & 0 & 48 & 0 & 237 \\
\hline & Proposed & & 28.745 & 30.491 & 29.802 & 29.794 & 0 & 39.538 & 39.195 & 40.228 & 0 & 238.027 \\
\hline \multirow[t]{2}{*}{527.80} & SLL & 3662 & 43 & 47 & 44 & 47 & 43 & 47 & 45 & 48 & 2622 & 364 \\
\hline & Proposed & & 45.659 & 45.597 & 45.628 & 45.61 & 0 & 45.612 & 45.642 & 45.636 & 2542 & 364.953 \\
\hline \multirow[t]{2}{*}{528.20} & SLL & 1560 & 40 & 0 & 35 & 37 & 39 & 34 & 26 & 31 & 869 & 242 \\
\hline & Proposed & & 49 & 49 & 49 & 49 & 49 & 49 & 49 & 49 & 440 & 392 \\
\hline \multirow[t]{2}{*}{528.27} & SLL & 1548 & 34 & 33 & 28 & 30 & 28 & 34 & 30 & 30 & 842 & 247 \\
\hline & Proposed & & 49 & 49 & 49 & 49 & 49 & 49 & 49 & 49 & 428 & 392 \\
\hline \multirow[t]{2}{*}{527.94} & SLL & 1460 & 41 & 43 & 42 & 46 & 43 & 47 & 43 & 42 & 474 & 347 \\
\hline & Proposed & & 49 & 49 & 49 & 49 & 49 & 49 & 49 & 49 & 340 & 392 \\
\hline
\end{tabular}




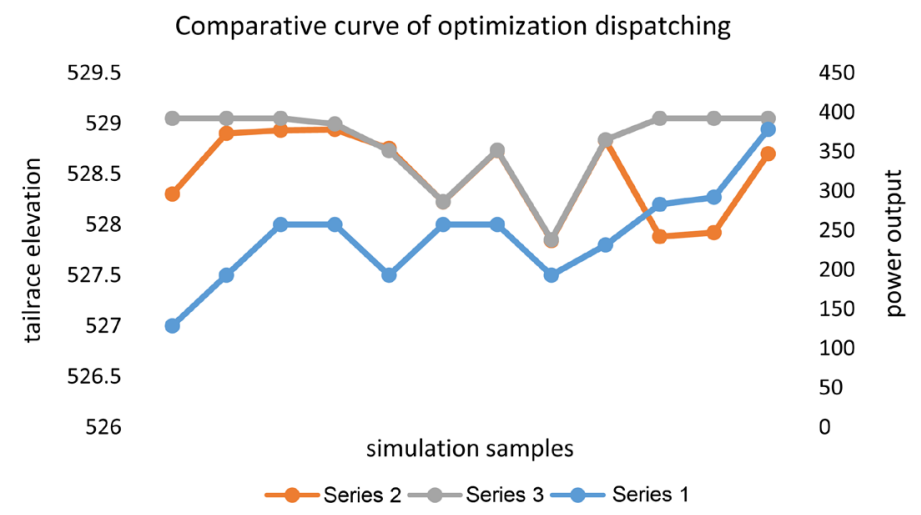

Figure 4. Comparative curve of optimimization dispatching of Songloulou hydro plant.

we carried out, we find ourselves roughly in the same range of values as on the Songloulou file. In the moments when the eight turbines work in the file, on our algorithm, the eight turbines also work. If a turbine is not working in the file, in our algorithm a turbine does not rotate either. Besides, when we have to open the discharge valve, our algorithm also proposes to open the discharge valve at the same time as in the file provided by Songloulou. Figure 4 presents the gap between our proposal algorithm against results of Songloulou hydro plant. Our program always maximizes production by avoiding deversing flow without producing the maximum power.

\section{Conclusion}

The increase in electricity production requires taking into account the operating conditions. The latter makes it possible to promote the longevity of the plant by avoiding untimely stops of one or more during the operation following a breakdown. In this work, the main objective was the maximizing of the production of the 8 groups of the Songloulou power station by taking into account the level of water availability in the upstream basin, the admissible area of each turbine, the stop/start of the system while respecting the operating conditions and the quantity of water evacuation not participating in the production. From these parameters used, we obtained convincing results with an increase in Songloulou production. This work did not take into account the criteria for group maintenance and loss of transmission of the power produced in the electrical network which will be the subject of our next study.

\section{Acknowledgements}

We are grateful with Electricity of Cameroon about the whole data using in this study and the operating system of Songloulou hydroelectric plant.

\section{Conflicts of Interest}

The authors declare no conflicts of interest regarding the publication of this paper. 


\section{References}

[1] Ruel, O.C. and Kamyogo, E.D. (2018) Environmental Law and Policy in Cameroon-Towards Making Africa the Tree of Life | Droit et politique de l'environnement au Cameroun-Afin de faire de l'Afrique l'arbre de vie. Nomos Verlagsgesellschaft Mbh. \& Co., Baden.

[2] Mbadjoun D.E., Wapet, S., Ndjakomo Essiane1, E. and Ntom Mentsouga, S. (2016) Perabi Ngoffe: Optimisation bi-objectif des centrales thermiques par une methode hybride incluant l'intelligence artificielle. Sciences, Technologies et Développement, Edition spéciale, 45-48.

[3] Guy, H., Kouokam, D.S., Ndjakomo, E., Daniel, E. and Mbadjoun, W. (2016) Application de l'algorithme de la colonie de fourmis dans l'optimisation économique et environnementale d'une centrale thermique. Sciences, Technologies et Développement, Edition spéciale, 65-69.

[4] Ntom, E., Mentsouga, S., Ndjakomo Essiane, D.E. and Mbadjoun Wapet, S. (2016) Perabi Ngoffe: Dispatching economique et environnemental par une approche du reseau de neurones de hopfield combinee a la methode de dichotomie. Sciences, Technologies et Développement, Edition spéciale, 147-150.

[5] Gnetchejo, P.J., Ndjakomo, S.E., Ele, P., Wamkeue, R., Wapet, D.M. and Perabi, S.P. (2019) Important Notes on Parameter Estimation of Solar Photovoltaic Cell. Energy Conversion and Management, 197, Article ID: 111870. https://doi.org/10.1016/j.enconman.2019.111870

[6] Gnetchejo, P.J., Ndjakomo, S.E., Ele, P., Wamkeue, R., Wapet, D.M. and Perabi, S.N. (2019) Enhanced Vibrating Particles System Algorithm for Parameters Estimation of Photovoltaic System. Journal of Power and Energy Engineering, 7, 1-26.

[7] Gnetchejo, P.J., Ndjakomo, S.E., Ele, P., Wamkeue, R., Wapet, D.M. and Perabi, S.N. (2019) Reply to "Comment on Important Notes on Parameter Estimation of Solar Photovoltaic Cell” [Energy Convers. Manage. 2019;197:111870] by Patrick Juvet Gnetchejo et al. Energy Conversion and Management, 201.

[8] Beluco, A., Souza, P. and Krenzinger, A. (2013) Influence of Different Degrees of Complementarity of Solar and Hydro Energy Availability on the Performance of Hybrid Hydro PV Generating Plants. Energy and Power Engineering, 5, 332-342. https://doi.org/10.4236/epe.2013.54034

[9] Matmurodov, F., Sobirov, B., Tulanov, I., Mirzaabdullayev, J., Khakimov, J. and Daminov, O. (2019) Mathematical Modeling of The Transfer of Energy forces from the Engine through Hydro Transmission and Hydro Differential to Executive Bodies. World Journal of Mechanics, 9, 105-112.

https://doi.org/10.4236/wjm.2019.95008

[10] Chang, W.P. (2010) A Novel Particle Swarm Optimization for Optimal Scheduling of Hydrothermal System. Energy and Power Engineering, 2, 223-229. https://doi.org/10.4236/epe.2010.24033

[11] Al-Bahadly, I. (2018) An Integrated Wind and Hydro Power System Using Switched Reluctance Generator. Journal of Power and Energy Engineering, 6, 1-19. https://doi.org/10.4236/jpee.2018.62001

[12] Hidalgo, I.G., Fontane, D.G., Arabi, M., Lopes, J.E.G. and Andrade, J.G.P. (2012) Evaluation of Optimization Algorithms to Adjust Efficiency Curves for Hydroelectric Generating Units. Journal of Energy Engineering, 138, 172-178. https://doi.org/10.1061/(ASCE)EY.1943-7897.0000074

[13] Sandor, B.I. and Susan-Resiga, R. (2012) Numerical Model for Cavitational Flow in Hydraulic Poet Valves. Modelling and Simulation in Engineering, 2012, Article ID: 
742162. https://doi.org/10.1155/2012/742162

[14] Nazari-Heris, M., Mohammadi-Ivatloo, B. and Gharehpetian, G.B. (2017) Short-Term Scheduling of Hydro-Based Power Plants Considering Alication of Heuristic Algorithms: A Comprehensive Review. Renewable and Sustainable Energy Reviews, 74, 116-129. https://doi.org/10.1016/j.rser.2017.02.043

[15] Diniz, A., Esteves, P.P. and Sagastizábal, C.A. (2007) A Mathematical Model for Efficiency Curves of Hydroelectric Units. 2007 IEEE Power Engineering Society General Meeting, 24-28 June 2007, Tampa, FL, 1-7. https://doi.org/10.1109/PES.2007.385632

[16] Mahor, A. and Rangnekar, S. (2009) Mathematical Modelling of Omkareshwor Hydro-Electric Plant at Narmada River. Hydro Nepal: Journal of Water, Energy and Environment, 3, 48-52. https://doi.org/10.3126/hn.v3i0.1906

[17] Horváth, K., Van Esch, B., Vreeken, D., Pothof, I. and Baayen, J. (2019) Convex Modeling of Pumps in Order to Optimize Their Energy Use. Water Resources Research, 55, 2432-2445. https://doi.org/10.1029/2018WR023811

[18] Diniz, A.L., Xavier, L.L. and Costa, F.S. (2007) Modelagem da função de produção energética das usinas hidroelétricas nos modelos de otimização do planejamento a curto prazo e da programação do despacho de sistemas hidrotérmicos interligados. Cadernos do IME-Série Estatística, 23, 1-15.

[19] Elbatran, A.H., Abdel-Hamed, M.W., Yaakob, O.B., Ahmed, Y.M. and Ismail, M.A. (2015) Hydro Power and Turbine Systems Reviews. Jurnal Teknologi, 74, 83-90.

[20] Parvez, I., Shen, J.J., Khan, M. and Cheng, C. (2019) Modeling and Solution Techniques Used for Hydrogeneration Scheduling. Water, 11, Article ID: 11392. https://doi.org/10.3390/w11071392

[21] Margonis, P. (2017) Modeling and Optimization of a Hydroelectric Power Plant for a National Grid Power System Suly. Case Study: Stratos Hydroelectric Dam. Diploma Work, School of Electrical and Computer Engineering, Technical University of Crete, Chania, Greece.

[22] Hildago, I., Soares, F.S., Fontane, D., Lopes, J.E., Cicigna, M. and Silva, F.D. (2012) Analysis of the Level-Release Polynomial from a Hydroelectric Plant. Systemics, $C y-$ bernetics and Informatics, 10, 62-65.

[23] Wamba, J.T. (2013) Modélisation and implémentation numérique du simulateur analogique de la centrale Hydro-Québec. Université du Québec en Abitibi-Témiscamingue, Québec.

[24] Jordehi, A.R. (2016) Time Varying Acceleration Coefficients Particle Swarm Optimisation (Tvacpso): A New Optimisation Algorithm for Estimating Parameters of PV Cells and Modules. Energy Conversion and Management, 129, 262-274. https://doi.org/10.1016/j.enconman.2016.09.085

[25] Séguin, S. (2016) Optimisation stochastique de la répartition spatio-temporelle d'un volume d'eau aux groupes turbo-alternateurs d'un système de production hydroélectrique, Montréal: Département de Mathématiques et de Génie Industriel, Ecole Polytechnique de Montréal. Université de Montréal, Montréal.

[26] Arvidsen, H.I. (2019) Hydropower Production Scheduling Using Stochastic Dual Dynamic Programming Subject to Environmental Constraints. Master Thesis, Electrical Department, Norway.

[27] Hammadia, A. (2000) Contribution à l'optimisation, en temps reel et à court terme, des des ressources hydroélectriques d'une rivière, thèse en Mathématiques de l'ingénieur, Canada.

[28] Séguin, S., Audet, C. and Côté, P. (2017) Scenariotree Modeling for Stochastic Short- 
Term Hydropower Operations Planning. Journal of Water Resources Planning and Management, 143, 112. https://doi.org/10.1061/(ASCE)WR.1943-5452.0000854

[29] Séguin, S., Fleten, S.E., Côté, P., Pichler, A. and Audet, C. (2017) Stochastic ShortTerm Hydropower Planning with Inflow Scenario Trees. European Journal of Operational Research, 259, 1156-1168. https://doi.org/10.1016/j.ejor.2016.11.028 


\section{Notation:}

The following notation is used throughout the paper:

$i=1,2, \cdots, n:$ Index of turbine

$l=1,2, \cdots, L:$ Index of network channel

$r$ Index of electrical network

$V$ Volume of water in upstream reservoir

$u$ Volume of water in downstream reservoir

$P$ power obtained in the conversion process of hydraulic potential energy into electric energy (MW)

$k$ gravity constant, multiplied by the water specific weight and divided by 106 \{its value is $0.00981\left[\mathrm{MW} /\left(\mathrm{m}^{3} / \mathrm{s}\right) / \mathrm{m}\right]$

$\eta_{t}$ turbine efficiency in the conversion process of kinetic energy into mechanical energy

$\eta_{g}$ generator efficiency in the conversion process of mechanical energy into electrical energy

$h_{f b}$ forebay elevation which is function of the water storage $(\mathrm{m}) ; V=$ water storage in the reservoir of plant $\left(\mathrm{hm}^{3}\right)$

$h_{t r}$ tailrace elevation which is function of the water release $(\mathrm{m}) ; u=$ water release by the turbines and the spillway of the plant

$h_{p l}$ penstock head loss which is function of the water discharge (m); and $q=$ water discharge by the turbines of the powerhouse $\left(\mathrm{m}^{3} / \mathrm{s}\right)$

$\eta^{G}$ unit efficiency considering the losses of the turbine generator set $\left(\eta_{t} \cdot \eta_{g}\right)$

$h_{g}$ difference between forebay elevation and tailrace elevation, that is $h_{f b}(V)-h_{t r}(u)$

$Q$ Flow discharge by unit

$Q_{T}$ Turbine flow discharged in the hydro plant

$Q_{r}$ Flow remaining after allocation

$D$ Unit interval of operation

$G$ Initial optimization problem

SC Optimization sub-problem 1

SR Optimization sub-problem 2

$D P$ required interval of production power

$J_{r}^{l}$ Active turbine during operation 